\title{
Quantitative evaluation of disease severity in connective tissue disease-associated interstitial lung disease by dual-energy computed tomography
}

Ling Chen ${ }^{1,2+}$, Min Zhu ${ }^{1,2+}$, Haiyan Lu ${ }^{1 \dagger}$, Ting Yang ${ }^{1}$, Wanjiang Li ${ }^{3}$, Yali Zhang ${ }^{1,2}$, Qibing Xie ${ }^{4}$, Zhenlin Li ${ }^{3}$, Huajing Wan ${ }^{1,2^{*}}$ and Fengming Luo ${ }^{1,2^{*}}$ (i)

\begin{abstract}
Background: High-resolution computed tomography (HRCT) is recommended diagnosing and monitoring connective tissue disease-associated interstitial lung disease (CTD-ILD). Quantitative computed tomography has the potential to precisely assess the radiological severity of CTD-ILD, but has still been under study.

Objective: To investigate whether dual-energy computed tomography (DECT), a novel quantitative technique, can be used for quantitative severity assessment in CTD-ILD.

Methods: This cross sectional study recruited adult CTD-ILD patients who underwent DECT scans from the ICE study between October 2019 and November 2021. DECT parameters, including effective atomic number ( $Z_{\text {eff }}$ ), lung (lobe) volume, and monochromatic CT number (MCTN) of each lung lobe, were evaluated. CTD-ILD was classified into extensive CTD-ILD and limited CTD-ILD by staging algorithm using combined forced vital capacity (FVC)\%predicted and total extent of ILD (TEI) on CT. Dyspnea, cough, and life quality were scored by Borg dyspnea score, Leicester cough questionnaire (LCQ), and short-form 36 health survey questionnaire (SF-36), respectively.

Results: There was a total of 147 patients with DECT scans enrolled. Higher $Z_{\text {eff }}$ value $(3.104$ vs $2.256, p<0.001)$, higher MCTN $(-722.87 \mathrm{HU}$ vs $-802.20 \mathrm{HU}, p<0.001)$, and lower lung volume $\left(2309.51 \mathrm{~cm}^{3}\right.$ vs $\left.3475.21 \mathrm{~cm}^{3}, p<0.001\right)$ were found in extensive CTD-ILD compared with limited CTD-ILD. DECT parameters had significant moderate correlations with FVC\%predicted $(|r|=0.542-0.667, p<0.01)$, DLCO\%predicted $(|r|=0.371-0.427, p<0.01)$, and TEl $(|r|=0.485-$ $0.742, p<0.01)$. Receiver operating characteristic (ROC) analysis indicated MCTN averaged over the whole lung had the best performance for extensive CTD-ILD discrimination (AUC $=0.901$, cut-off: $-762.30 \mathrm{HU}, p<0.001$ ), with a sensitivity of $82.1 \%$ and a specificity of $85.4 \%$. The $Z_{\text {eff }}$ value was the independent risk factor for dyspnea $(O R=3.644$, $95 \% \mathrm{Cl}: 1.846-7.192, \mathrm{p}<0.001)$ and cough $(\mathrm{OR}=3.101,95 \% \mathrm{Cl}: 1.528-6.294, \mathrm{p}=0.002)$, and lung volume significantly contributed to the mental component summary (MCS) in SF-36 (standardized $\beta=0.198, p<0.05$ ).
\end{abstract}

Conclusions: DECT can be applied to evaluate the severity of CTD-ILD.

\footnotetext{
*Correspondence: wanhuajing1974@wchscu.cn; fengmingluo@outlook.com

${ }^{+}$Ling Chen, Min Zhu and Haiyan Lu contributed equally to this work and

are co-first authors

1 Department of Respiratory and Critical Care Medicine, West China

Hospital, Sichuan University, No. 37 Guo Xue Xiang, Chengdu 610041,

China

Full list of author information is available at the end of the article
} original author(s) and the source, provide a link to the Creative Commons licence, and indicate if changes were made. The images or other third party material in this article are included in the article's Creative Commons licence, unless indicated otherwise in a credit line to the material. If material is not included in the article's Creative Commons licence and your intended use is not permitted by statutory regulation or exceeds the permitted use, you will need to obtain permission directly from the copyright holder. To view a copy of this licence, visit http://creativecommons.org/licenses/by/4.0/. The Creative Commons Public Domain Dedication waiver (http://creativeco mmons.org/publicdomain/zero/1.0/) applies to the data made available in this article, unless otherwise stated in a credit line to the data. 
Keywords: Connective tissue disease-associated interstitial lung disease (CTD-ILD), Dual-energy computed tomography (DECT), Lung volume (LV), Effective atomic number $\left(Z_{\text {eff }}\right)$, Monochromatic CT number (MCTN)

\section{Background}

Connective tissue disease-associated interstitial lung disease (CTD-ILD) is a predominant type of ILD [1], as well as a common and serious pulmonary complication of CTD [2, 3]. It has been reported to be the leading cause of significant morbidity and mortality of CTD [4], constituting $31.76 \%$ mortality of this disease [5]. The survival time of CTD-ILD patients was 1.7 times shorter than CTD patients without ILD [5]. The severity of ILD is usually associated with poor outcome and life quality of CTD-ILD patients [6, 7]. Therefore, accurate evaluation of ILD severity may provide evidence for the appropriate clinical decision in the diagnosing and monitoring of CTD-ILD patients.

Pulmonary function test (PFT) and high-resolution computed tomography (HRCT) have been still the two major tools to diagnose and evaluate CTD-ILD in clinical practices, rather than lung biopsy [8]. Declines of PFTs, such as forced vital capacity (FVC), vital capacity, and diffusing capacity of the lungs for carbon monoxide (DLCO), are predictors for exacerbations and mortality in ILD [9]. But the results of PFTs weakly reflect the extent of ILD [9] and could be confounded by the presence of comorbidities, such as pleural disease [10], chronic airway diseases, pulmonary hypertension, or anemia $[11,12]$. Furthermore, given that the measures of PFT heavily rely on the cooperation of patients [13], PFT is not applicable to some severe patients. HRCT can define different radiological patterns and distribution of ILD abnormalities, which is fundamental to the diagnosis and monitoring of ILDs. Increased extent of fibrotic abnormalities, including honeycombing, reticulation, and traction bronchiectasis, were predictors of worse prognosis in ILD [14, 15]. However, most assessments in the above studies were visual or semi-quantitative analysis, which was subjective evaluation, and relied on experienced radiologists or pulmonologists [16]. Recently, there have been several quantitative assessment methods under investigation, like quantitative lung fibrosis (QLF) score [17], and computer-aided lung informatics for pathology evaluation and ratings (CALIPER) [18], but these methods require additional professional software and senior radiologists or pulmonologists. Therefore, it is worth exploring a more precise and convenient quantitative evaluation technology.

In conventional $\mathrm{CT}$ imaging, the only quantitative value we can obtain in the images is the CT number. It is a calculated value reflecting the X-ray attenuation coefficient in an image voxel, representing the combination of atomic number of the materials and their density. As such, different materials with different atomic numbers on different densities may generate same CT number. It is challenging for CT number to differentiate and classify different types of tissues. Dual-energy computed tomography (DECT) $[19,20]$ was introduced to overcome the shortcomings of conventional $\mathrm{CT}$ by generating multiple imaging parameters to differentiate and classify a mixture of different materials without additional dose or compromised image quality [21]. The imaging parameters in DECT include the effective atomic number $\left(\mathrm{Z}_{\text {eff }}\right)$, monochromatic CT number (MCTN), and lung lobe volume, etc. The $\mathrm{Z}_{\text {eff }}$ value reflects the intrinsic composition of a material, allowing the application of atomic number to answer what the material is. It is independent on the photon energy and relates to the mix of elements that will be in the voxel. MCTN is the CT numbers generated from monochromatic images in DECT. The monochromatic image depicts how the imaged object would look when the X-ray source produced only X-ray photons at a single energy. This allows MCTN better represents the true attenuation of materials to X-ray beams. Lung lobe volume reflects lung compliance, which allows the evaluation of ventilation function. And DECT has been demonstrated to simultaneously provide the lung function information, as well as the anatomic information in pulmonary diseases [22]. Up to now, DECT has shown its clinical applications value in malignant lung lesions, chronic airway diseases, pulmonary embolism, and pulmonary ventilation abnormalities [25-28]. However, its value in interstitial lung disease is still unknown.

Considering the ability of DECT to structurally and functionally image lung lesions, we hypothesized that DECT could be applied in CTD-ILD severity assessment. To test this hypothesis, DECT parameters in different severity of CTD-ILD patients were evaluated, and the correlations of DECT parameters with the levels of PFTs, the extent of ILD, manifestations of respiratory symptoms (dyspnea and cough) and life quality levels were investigated, respectively.

\section{Material and methods Study design and subjects}

This cross sectional study was designed to explore whether DECT parameters could reflect the severity of CTD-ILDs evaluated by CT, PFTs (FVC\%predicted and DLCO\%predicted), symptoms scales (dyspnea 
scored by Borg dyspnea score, cough scored by Leicester cough questionnaire (LCQ)), and life quality scale (36 items short form health survey (SF-36)). This study was approved by Ethics Committee on Biomedical Research (2020-216) at West China Hospital, and all the patients had written informed consent.

A total of 147 adult stable CTD-ILD patients with DECT scans were enrolled, followed up in ICE study (Interstitial lung disease in West China Hospital: a 24-month prospective Cohort on the $\mathrm{rEal}$ world) between October 2019 and November 2021. The diagnosis of CTD-ILD was determined by the ILD multidisciplinary group with experts in radiology, pathology, rheumatology, and pulmonology according to CTDILD position statement from the Thoracic Society of
Australia and New Zealand [2] and the official statement of the European Respiratory Society/American Thoracic Society for interstitial pneumonia with autoimmune features (IPAF) [30]. Exclusion criteria included idiopathic ILD, ILD for other causes (such as sarcoidosis, drug, toxicity, or PAP), acute exacerbation of interstitial lung disease according to the International Working Group Report of acute exacerbation of idiopathic pulmonary fibrosis [31], pulmonary infection, heart failure [32] to avoid the influence on the DECT parameters; refused consent; or missing DECT scan data. Figure 1 showed the process of patients screening. The lung images data of healthy people from a health checking program was also included in the stratification analysis.

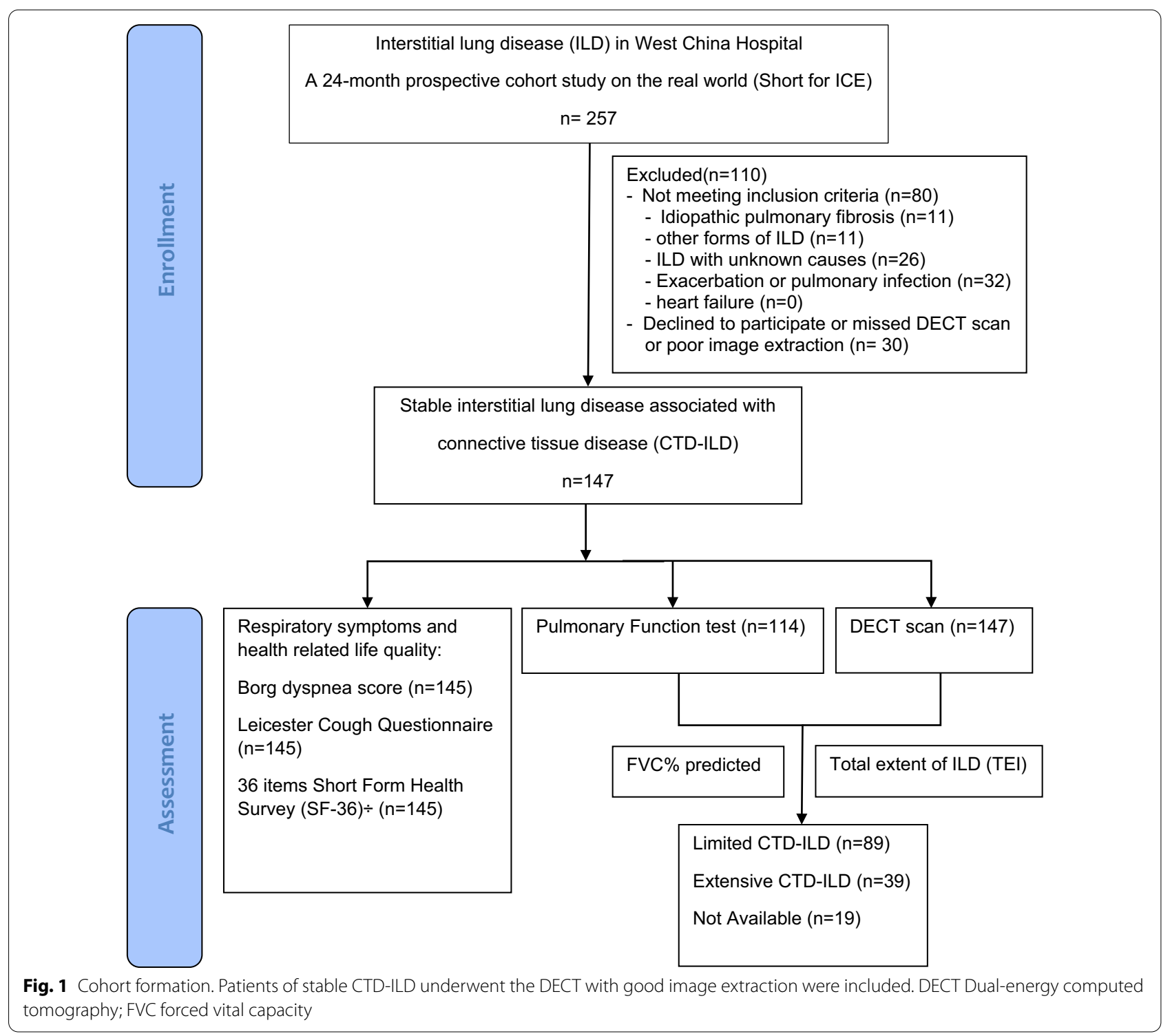




\section{Data collection}

The demographics and clinical characteristics were reviewed by the well-trained researchers, including basic information (age, sex, body mass index, smoking history), respiratory symptoms (dyspnea and cough), quality of life (SF-36, consisting of physical component summary (PCS) and mental component summary (MCS), common comorbid conditions (chronic obstructive pulmonary disease, coronary artery disease, diabetes mellitus, hypothyroidism, anemia, etc.). Dyspnea was classified into no dyspnea (Borg dyspnea score $=0)$, mild dyspnea $(0<$ Borg dyspnea score $\leq 2$ ) and moderate to severe dyspnea (Borg dyspnea score $\geq 3$ ). Cough was classified into no cough $(\mathrm{LCQ}=0)$, mild cough $(\mathrm{LCQ} \geq 17)$ and severe cough $(0<\mathrm{LCQ}<17)$ [33].

Pulmonary function test was conducted according to the recommendations of the American Thoracic Society/European Respiratory Society [34]. The combination of FVC\%predicted and DLCO\%predicted was classified into mild (FVC\%predicted $\geq 80 \%$ and $\quad$ DLCO\%predicted $\geq 80 \%$ ), moderate (FVC\%predicted $>50 \%$ and DLCO \%predicted $>50 \%$ and not the mild cases), and severe (FVC\%predicted $\leq 50 \%$ or DLCO\%predicted $\leq 50 \%$ ), respectively.

\section{Image acquisition with DECT}

All patients were scanned on a 256-slice CT scanner (Revolution CT, GE Healthcare, Milwaukee WI, USA) without contrast injection according to standards set. The DECT was obtained with the following parameters: fast switching between tube voltages of 80 and $140 \mathrm{kV}$, automatic $\mathrm{mA}$ selection for obtaining a noise index (NI) of 15 , the spiral pitch of 0.984 , tube rotation time of $0.5 \mathrm{~s}$, and detector width of $80 \mathrm{~mm}(128 \times 0.625 \mathrm{~mm})$. Images were reconstructed using a "detail" kernel with a slice thickness of $1.25 \mathrm{~mm}$ and a reconstruction interval of $0.625 \mathrm{~mm}$.

The DECT images were transferred to an advanced workstation (ADW4.7) equipped with the Gemstone Spectral Imaging (GSI) for post-processing. The data processing step included lung extraction and segmentation with identification and extraction of central airways and manual segmentation of the anatomical lobes in the thoracic analysis software. The segmentation of the lung was achieved into the right upper lobe (RU), right middle lobe (RM), right lower lobe (RL), left upper lobe (LU), left lower lobe (LL) using an adaptive density-based morphological approach. The corresponding DECT parameters of each lung lobe were achieved according to the extracted histogram, such as lung lobe volume, the mean, minimum, maximum values of the effective atomic number $\left(\mathrm{Z}_{\mathrm{eff}}\right)$, and the monochromatic CT number (MCTN) at the $70 \mathrm{keV}$ energy level (Fig. 2).

\section{The extent of ILD}

The extent of ILD was visually scored at five levels (origin of great vessels, the main carina, the pulmonary venous confluence, halfway between the third and fifth sections, and immediately above the right hemidiaphragm), and the total extent of ILD (TEI) on DECT was calculated as the mean of the five scores, according to the previous ILD staging system. The extent of the abnormalities was estimated to be the nearest $5 \%$ in each section. $20 \%$ was selected to be the TEI threshold of severe, and TEI > $20 \%$ was proved to be the powerful predictor of mortality. All semi-quantitative image evaluations of ILD were performed by two independent readers (LC with 7 years, TY with 12 years of experience in thoracic CT diagnosis). Discordances were settled by consensus.

\section{Severity assessment of CTD-ILD}

Limited/extensive staging system combined TEI and PFTs has greater mortality prognostic value compared with either TEI or PFT [36], and associates with the decline in FVC [37], so it is widely recommended to assess the severity of CTD-ILD. According to this staging system, TEI on CT is the preliminary analysis to identify cases readily classifiable into limited disease $(\mathrm{TEI} \leq 10 \%)$ or extensive disease (TEI $>30 \%$ ). For indeterminate TEI defined as TEI ranging from 10 to $30 \%$, FVC\%predicted with cut-off value $70 \%$ is combined. Thus, the CTDILD was staged as limited disease $(\mathrm{TEI} \leq 10 \%$, or indeterminate TEI with FVC\%predicted $\geq 70 \%$ ), or extensive disease (TEI $>30 \%$, or indeterminate TEI with FVC\%predicted $<70 \%$ ), which represented the mild, or severe CTD-ILD, respectively.

\section{Statistical analysis}

Continuous variables were presented as means \pm SD or median (range). Count variables were presented as frequency or percentage. Differences were analyzed using the student's t-test or ANOVA for continuous variables (LSD test was used for multiple comparisons), or chisquare test for count variables. Pearson correlation coefficients ( $r$ values) or Spearman correlation coefficients was used to quantify the correlation. Binary logistic regression was performed to study the association between DECT parameters and onset of dyspnea or cough symptom. Linear regression analysis was performed to determine the prediction of DECT parameters to the SF-36 in CTD-ILD patients. Receiver operating characteristics (ROC) analysis was performed to determine the area under the curve (AUC) for the diagnostic performance of DECT to differentiate the extensive from limited 

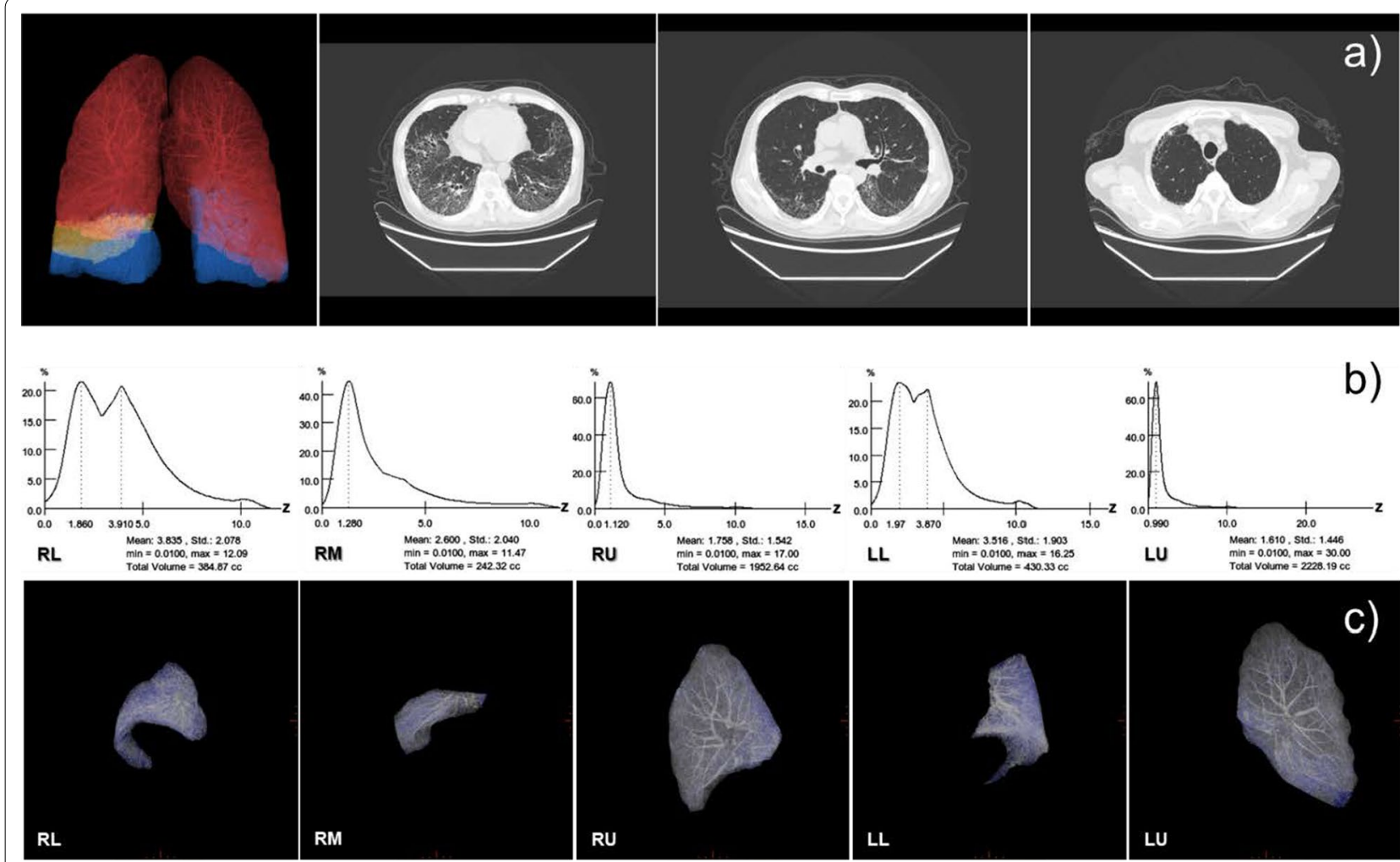

Fig. 2 The component distribution histograms of DECT parameter in a 66-year-old man, diagnosed with interstitial lung disease associated with MCTD (PM/DM and Sjögren syndrome). Row a presents colored split lung lobes in 3D and axial computed tomographic images of the chest at the three levels. The histograms of $Z_{\text {eff }}$ value were shown in Row $\mathbf{b}$. Compared with each other, shape of the histogram in lower lung lobes with complex lesions was wider, the mean value was higher and the wave peaks are more than those of the middle and upper lung lobes. In RL, RM, RU, LL, LU order, the mean $Z_{\text {eff }}$ value was 3.835, 2.600, 1.758, 3.516 and 1.610 respectively. Row c presented each lung lobe along with bronchovascular bundle in three-dimension (3D), and blue represents the interstitial lung abnormalities

CTD-ILD. All data were presented for statistical analysis using SPSS 20.0 (IBM, Armonk, NY, USA). Differences corresponding to $p<0.05$ were considered significant.

\section{Results}

\section{Demographic and clinical characteristics}

A total of 147 adult stable CTD-ILD patients with DECT scans were enrolled (Fig. 1), with 102 specific CTD (SCTD)-ILD, 30 IPAF, and 15 mixed CTD (MCTD)-ILD (Table 1). They were female predominant $(89.8 \%)$, with a mean age of $50.10 \pm 9.64$ years old and BMI $23.10 \pm 3.29 \mathrm{~kg} / \mathrm{m}^{2}, 11.6 \%$ with a smoking history, and 59.2\% with comorbid conditions. Mean FVC\%predicted was $89.59 \% \pm 22.94 \%$, and median DLCO\%predicted was $74.55 \%$ (ranged from $58.13 \%$ to $84.48 \%$ ). Combined with semi-quantitative chest CT assessment and FVC\% predicted, 89 (60.5\%) CTDILD patients were segregated into limited CTD-ILD, 39 (26.5\%) extensive CTD-ILD and 19 (13.0\%) unclassifiable for unavailable data. In available Borg dyspnea scores and LCQ scores, 69 (47.0\%) patients had dyspnea, $64(43.5 \%)$ had cough. The median PCS score of SF-36 was 51.80, ranged from 45.28 to 56.99 , and the median MCS score of SF-36 was 52.33, ranged from 43.97 to 57.53 .

\section{DECT parameters in different severity of CTD-ILDs}

Differences of DECT parameters in different severity of CTD-ILDs were analyzed. According to the limited/ extensive staging system combined TEI and PFTs, the extensive CTD-ILD patients (TEI $>30 \%$, or indeterminate TEI with $\mathrm{FVC} \%$ predicted $<70 \%$ ) were shown to have significantly lower volume $\left(2309.51 \mathrm{~cm}^{3}\right.$ vs $3475.21 \mathrm{~cm}^{3}$, $p<0.001$ ), higher $\mathrm{Z}_{\text {eff }}$ value (3.104 vs $2.256, p<0.001$ ), and higher MCTN $(-722.87 \mathrm{HU}$ vs $-802.20 \mathrm{HU}, p<0.001)$ in the whole lung, as well as each lung lobe (Table 2), when compared with limited CTD-ILDs (TEI $\leq 10 \%$, or indeterminate TEI with FVC\%predicted $\geq 70 \%$ ). According to the classification of TEI or PFT respectively, the severe CTD-ILD patients (TEI $>20 \%$ for extent; 
Table 1 Connective tissue disease associated interstitial lung disease (CTD-ILD) cohort demographic and clinical characteristics

\begin{tabular}{|c|c|}
\hline Demographic and clinical characteristics & $\begin{array}{l}\text { Mean } \pm \text { SD or N } \\
\text { (\%) or Median } \\
\text { (range) }\end{array}$ \\
\hline Age (year) & $50.10 \pm 9.64$ \\
\hline Female, No. (\%) & $132(89.8)$ \\
\hline BMI $\left(\mathrm{kg} / \mathrm{m}^{2}\right)^{\S}$ & $23.10 \pm 3.29$ \\
\hline Ethnicity (Han nationality), No. (\%) & $136(92.5)$ \\
\hline Former/current smoker, No. (\%) & $17(11.6)$ \\
\hline Comorbidity, No. (\%) & $87(59.2)$ \\
\hline \multicolumn{2}{|l|}{ Type of CTD } \\
\hline Specific CTD (SCTD) & $102(69.4)$ \\
\hline Systemic sclerosis/scleroderma (SSc) & $33(22.4)$ \\
\hline Polymyositis/dermatomyositis (PM/DM) & $39(26.5)$ \\
\hline Sjögren Syndrome (SjS) & $10(6.8)$ \\
\hline Rheumatoid Arthritis (RA) & $11(7.5)$ \\
\hline Systemic lupus erythematosus (SLE) & $9(6.1)$ \\
\hline Undifferentiated CTD (UCTD) & $30(20.4)$ \\
\hline Mixed CTD (MCTD) & $15(10.2)$ \\
\hline \multicolumn{2}{|l|}{ Dyspnea (Borg dyspnea score) } \\
\hline No dyspnea & $76(51.7)$ \\
\hline Mild dyspnea & $53(36.1)$ \\
\hline Moderate to Severe dyspnea & $16(10.9)$ \\
\hline NA & $2(1.4)$ \\
\hline \multicolumn{2}{|l|}{ Cough (LCQ) } \\
\hline No cough & $81(55.1)$ \\
\hline Mild cough & $39(26.5)$ \\
\hline Severe cough & $25(17.0)$ \\
\hline NA & $2(1.4)$ \\
\hline \multicolumn{2}{|l|}{ Pulmonary Function Test $\mathbb{q}$} \\
\hline FVC\% predicted & $89.59 \pm 22.94$ \\
\hline FEV $_{1} \%$ predicted ${ }^{\natural}$ & $87.50 \pm 21.14$ \\
\hline TLC\%predicted $\rrbracket$ & $85.80 \pm 19.40$ \\
\hline DLCO\% predicted ${ }^{+}$ & $74.55(58.13,84.48)$ \\
\hline \multicolumn{2}{|l|}{ Severity of CTD-ILD } \\
\hline Limited CTD-ILD & $89(60.5)$ \\
\hline Extensive CTD-ILD & $39(26.5)$ \\
\hline NA & $19(13.0)$ \\
\hline \multicolumn{2}{|l|}{$\mathrm{SF}-36^{\lambda}$ (range $\left.0-100\right)$} \\
\hline Physical component summary (PCS) score & $51.80(45.28,56.99)$ \\
\hline Mental component summary (MCS) score & $52.33(43.97,57.53)$ \\
\hline \multicolumn{2}{|c|}{ Data are presented as mean \pm SD or $n(\%)$ or Median (range) } \\
\hline \multicolumn{2}{|c|}{$\begin{array}{l}\text { Total-No. }=147 \text {, unless otherwise stated; } \S: N=146 ; \lambda: N=145 ; \text { १: } N=114 ;+: \\
N=112\end{array}$} \\
\hline \multicolumn{2}{|c|}{$\begin{array}{l}\text { BMI body mass index, CTD connective tissue disease, } I L D \text { interstitial lung disease } \\
L C Q \text { Leicester cough questionnaire, } F V C \text { forced vital capacity, } F E V_{1} \text { forced } \\
\text { expiratory volume in one second, } T L C \text { total lung capacity, } D L C O \text { diffusion } \\
\text { capacity of the lung for carbon monoxide, SF-36 } 36 \text { item short form health } \\
\text { survey, NA not available }\end{array}$} \\
\hline
\end{tabular}

FVC\%predicted $\leq 50 \%$ or DLCO $\%$ predicted $\leq 50 \%$ for PFT) also had significant lower volume, higher $\mathrm{Z}_{\text {eff }}$ value, and higher MCTN compared with moderate and mild patients (TEI $\leq 20 \%$ for extent; FVC\%predicted $>50 \%$ and DLCO\%predicted $>50 \%$ for PFT) (Additional file 1: Table S1 and S2). Bilateral lower lungs of extensive ILD had the significantly smallest lobe volume, highest $\mathrm{Z}_{\text {eff }}$ value and MCTN when compared to those of limited ILD and normal lung images. And the lobe volumes and absolute values of MCTN in bilateral lower lung lobes decreased as the severity increased ( $p$ for linear trend $<0.01$ ) (Additional file 1: Table S3).

The correlations of DECT parameters in whole lung and each lung lobe with PFT and semi-quantitative chest CT assessment were summarized in Additional file 1: Table S4. Figure 3 showed the LV positively correlated with VC $(\mathrm{r}=0.8923, p<0.0001)$, TLC $(\mathrm{r}=0.8721$, $p<0.0001)$, FVC $(\mathrm{r}=0.8901, p<0.0001)$ and DLCO $(\mathrm{r}=0.6991, p<0.0001)$, meanwhile $\mathrm{Z}_{\text {eff }}$ value and MCTN negatively correlated with $\mathrm{FVC} \%$ predicted $(\mathrm{r}=-0.5423$, $p<0.0001$ for $\mathrm{Z}_{\text {eff }}$ value; $\mathrm{r}=-0.5819, p<0.0001$ for MCTN). The $\mathrm{Z}_{\text {eff }}$ value and MCTN showed a significantly high positive correlation with TEI $(\mathrm{r}=0.7119, p<0.01$ for $\mathrm{Z}_{\text {eff }}$ value; $\mathrm{r}=0.7420, p<0.001$ for $\mathrm{MCTN}$ ).

Among DECT parameters significantly differentiating extensive from limited CTD-ILDs, the $Z_{\text {eff }}$ value and MCTN averaged over the whole lung, and those at middle lobe and lower lobes had higher AUCs (ranged from 0.864 to $0.901, p<0.001$ ) than lung (lobe) volume or those of upper lobes, shown in Fig. 4 and Additional file 1: Table S5. And the MCTN averaged over the whole lung (cutoff value $=-762.30 \mathrm{HU}$ ) achieved the highest AUC (0.901, 95\%CI: $0.850-0.952)$, with a sensitivity of $82.1 \%$ and a specificity of $85.4 \%$, to detect extensive CTD-ILD.

\section{DECT parameters' performance in different symptoms of CTD-ILDs}

The CTD-ILD patients with both dyspnea and cough had significantly smallest total lung volume $(p=0.003)$, highest $\mathrm{Z}_{\text {eff }}$ value $(p=0.000)$, and highest $\operatorname{MCTN}(p=0.000)$ when compared with no respiratory symptom and one respiratory symptom, shown in Table 3 . The similar trends were also shown in patients with severe dyspnea (Additional file 1: Table S6). Univariate analysis suggested that $\mathrm{Z}_{\text {eff }}$ value and MCTN were the risk factors for dyspnea and cough. MCTN was excluded in the multivariate analysis due to the significant collinearity with $Z_{\text {eff }}$ value. The multivariate analysis suggested that $Z_{\text {eff }}$ value was the independent risk factor for dyspnea $(\mathrm{OR}=3.644,95 \%$ CI: $1.846-7.192, p=0.000)$ and cough $(\mathrm{OR}=3.101,95 \%$ CI: $1.528-6.294, p=0.002)$. In the same way, the multivariate analysis included MCTN was performed with 
Table 2 Comparison the chest DECT parameters between limited CTD-ILD and extensive CTD-ILD

\begin{tabular}{|c|c|c|c|c|}
\hline & Limited CTD-ILD & Extensive CTD-ILD & $t / x^{2}$ & $p$ \\
\hline Total-No & 89 & 39 & & \\
\hline Age (year) & $49.44 \pm 9.27$ & $51.64 \pm 11.55$ & -1.146 & .254 \\
\hline BMI $\left(\mathrm{kg} / \mathrm{m}^{2}\right)$ & $23.49 \pm 3.09$ & $22.53 \pm 3.64$ & 1.515 & .132 \\
\hline Female, №. (\%) & $78(87.6 \%)$ & $38(97.4 \%)$ & 3.062 & .080 \\
\hline Han nationality, No. (\%) & $86(96.6 \%)$ & $35(89.7 \%)$ & 2.487 & .115 \\
\hline Former/current smoker, No. (\%) & $14(15.7 \%)$ & $0(0)$ & 6.888 & .009 \\
\hline Comorbidity, No. (\%) & $52(58.4 \%)$ & $24(61.5 \%)$ & 0.109 & .741 \\
\hline Lung volume $\left(\mathrm{cm}^{3}\right)$ & $3475.21 \pm 971.62$ & $2309.51 \pm 668.98$ & 7.844 & .000 \\
\hline$V_{-} R L$ & $607.08 \pm 275.18$ & $278.39 \pm 136.74$ & 9.012 & .000 \\
\hline V_RM & $377.19 \pm 138.00$ & $287.47 \pm 144.82$ & 3.335 & .001 \\
\hline V_RU & $901.38 \pm 249.48$ & $742.69 \pm 262.74$ & 3.259 & .001 \\
\hline V_LL & $548.31 \pm 255.13$ & $254.51 \pm 120.13$ & 8.853 & .000 \\
\hline V_LU & $1041.24 \pm 284.10$ & $746.45 \pm 316.93$ & 5.215 & .000 \\
\hline Average $Z_{\text {eff }}$ value & $2.256 \pm 0.435$ & $3.104 \pm 0.569$ & -8.311 & .000 \\
\hline Z_RL & $2.682 \pm 0.653$ & $3.828 \pm 0.813$ & -8.470 & .000 \\
\hline Z_RM & $2.018 \pm 0.382$ & $2.833 \pm 0.692$ & -6.906 & .000 \\
\hline Z_RU & $1.911 \pm 0.327$ & $2.501 \pm 0.567$ & -6.071 & .000 \\
\hline Z_LL & $2.706 \pm 0.663$ & $3.792 \pm 0.698$ & -8.398 & .000 \\
\hline Z_LU & $1.961 \pm 0.334$ & $2.566 \pm 0.629$ & -5.664 & .000 \\
\hline Average MCTN (HU) & $-802.20 \pm 40.27$ & $-722.87 \pm 52.83$ & -8.373 & .000 \\
\hline MCTN_RL & $-760.08 \pm 63.10$ & $-654.62 \pm 75.83$ & -8.173 & .000 \\
\hline MCTN_RM & $-825.56 \pm 35.10$ & $-749.33 \pm 61.82$ & -7.209 & .000 \\
\hline MCTN_RU & $-836.07 \pm 29.22$ & $-781.03 \pm 54.10$ & -5.982 & .000 \\
\hline MCTN_LL & $-757.79 \pm 63.46$ & $-654.72 \pm 69.34$ & -8.221 & .000 \\
\hline MCTN_LU & $-831.51 \pm 28.42$ & $-774.64 \pm 60.19$ & -5.631 & .000 \\
\hline
\end{tabular}

Total-No. $=128$

$D E C T$ dual-energy computed tomography, CTD-ILD connective tissue disease-associated interstitial lung disease, $B M I$ body mass index, $V \_R L$ volume of right lower lung lobe, $V \_R M$ volume of right middle lung lobe, $V_{-} R U$ volume of right upper lung lobe, $V_{-} L L$ volume of left lower lung lobe, $V \_L U$ volume of left upper lung lobe, $Z$ $R L Z_{\text {eff }}$ value of right lower lung lobe, $Z_{-} R M Z_{\text {eff }}$ value of right middle lung lobe, $Z_{-} R U Z_{\text {eff }}$ value of right upper lung lobe, $Z_{-} L L Z_{\text {eff }}$ value of left lower lung lobe, $Z_{-} L U Z_{\text {eff }}$ value of left upper lung lobe, $M C T N$ monochromatic CT number at $70 \mathrm{keV}, M C T N \_R L$ monochromatic CT number of right lower lung lobe, $M C T N \_R M$ monochromatic $C T$ number of right middle lung lobe, $M C T N \_R U$ monochromatic CT number of right upper lung lobe, MCTN_LL monochromatic CT number of left lower lung lobe, MCTN_LU monochromatic CT number of left upper lung lobe

$\mathrm{Z}_{\text {eff }}$ value excluded (Additional file 1: Tables S10 and S11, Tables 4, 5).

\section{DECT parameters contribute to the life quality of CTD-ILDs}

The SF-36 health survey is an approach to measure life quality, and recommended for CTD-ILD patients. It was shown in our study that DECT parameters (LV, average $\mathrm{Z}_{\text {eff }}$ value, and average MCTN) significantly correlated with PCS score of SF-36 $(p<0.05$, Additional file 1: Table S4), with $|r|$ ranging from 0.231 to 0.283 . The linear regression models showed that LV (standardized $\beta=0.198, p=0.012$ ) significantly contributed to the mental component summary (MCS) adjusted for age, gender, BMI, smoke, type of CTD and respiratory symptoms (Additional file 1: Table S9).

\section{Discussion}

To our knowledge, this is the first research to evaluate the application value of unenhanced DECT with GSI in CTD-ILD patients. In this study, we showed that DECT parameters could reflect the clinical severity of CTDILD patients: increased severity of CTD-ILD assessed by symptoms, CT, and PFT significantly associated with reduced $L V$, elevated $Z_{\text {eff }}$ value and increased MCTN. $Z_{\text {eff }}$ value and MCTN had robust differentiation capacity to detect extensive CTD-ILD from limited CTD-ILD. Additionally, higher $\mathrm{Z}_{\text {eff }}$ value was the independent risk factor for dyspnea and cough in CTD-ILD patients. Lung volume reduction could reflect the CTD-ILD patients' life quality.

In our study, DECT parameters could achieve excellent performance in terms of differentiating extensive from limited CTD-ILDs. The pathological basis of interstitial lung disease was pulmonary alveolar unit inflammation 
a)

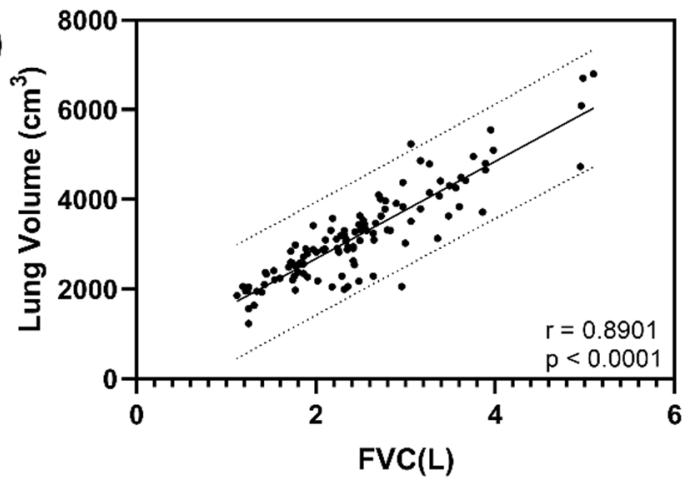

c)

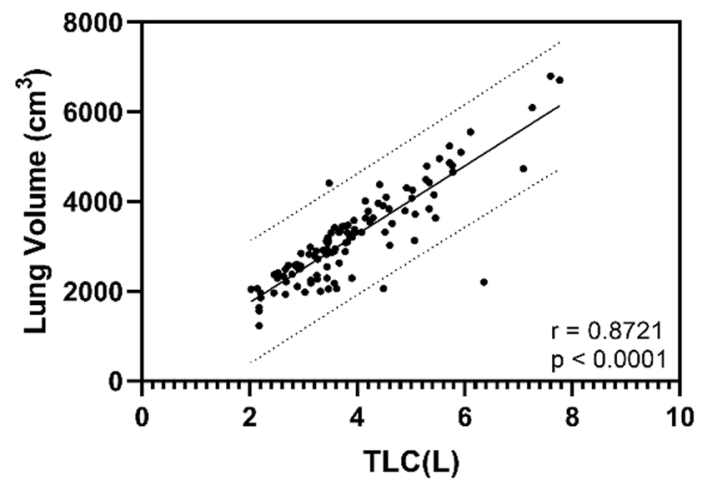

e)

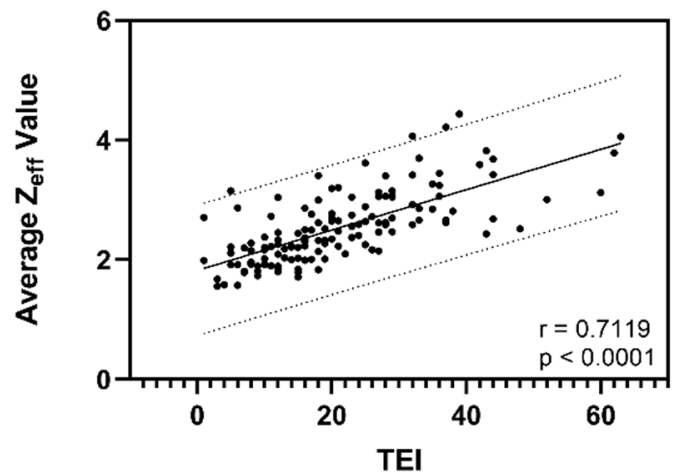

g)

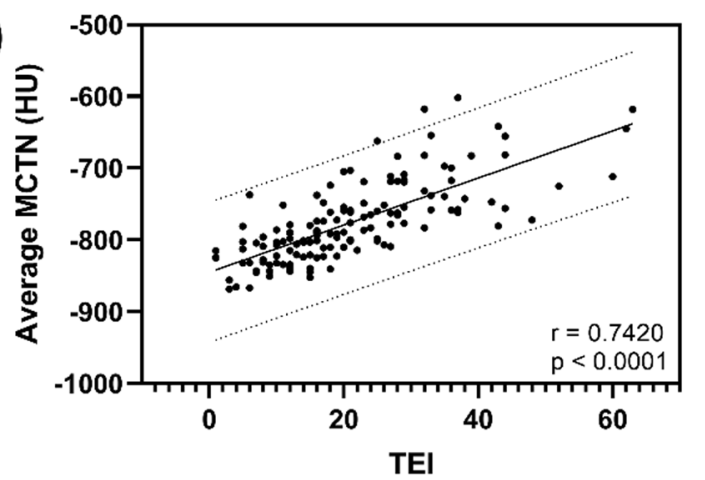

b)

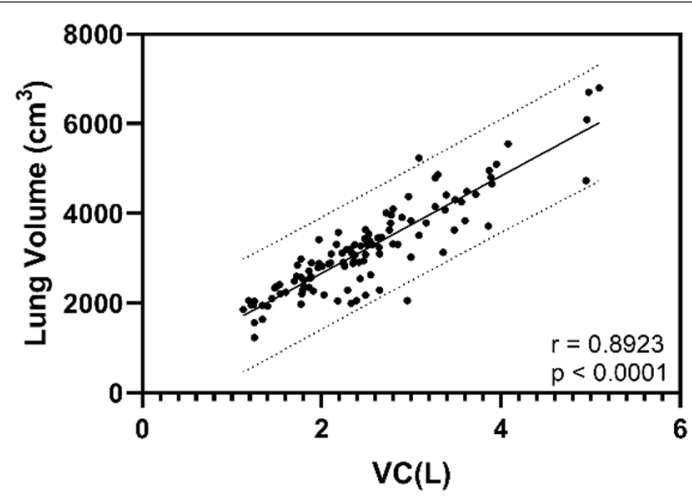

d)

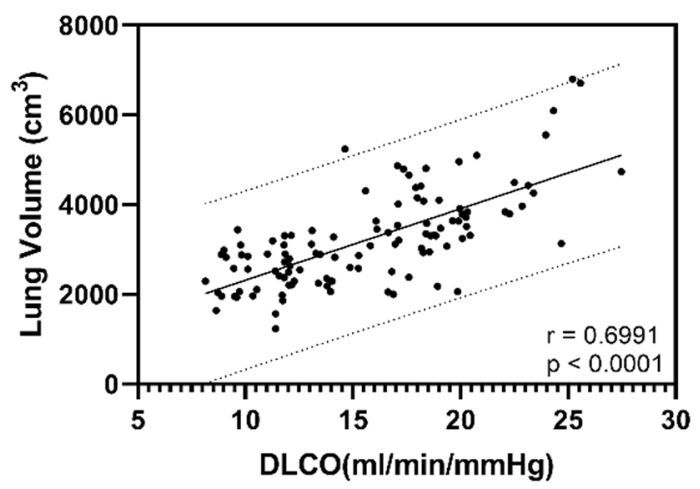

f)

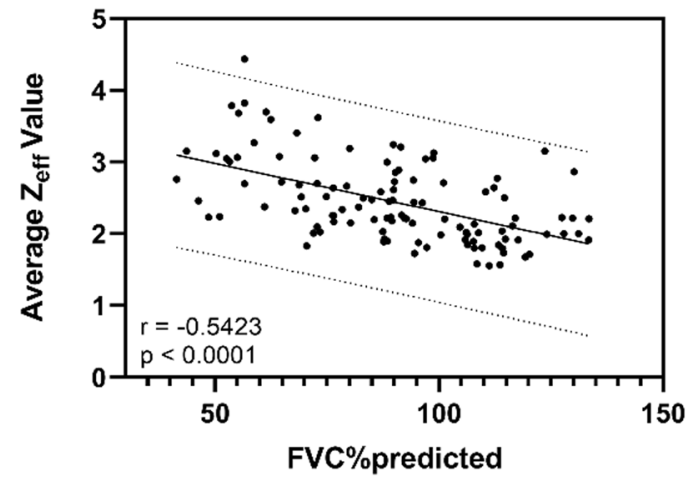

h)

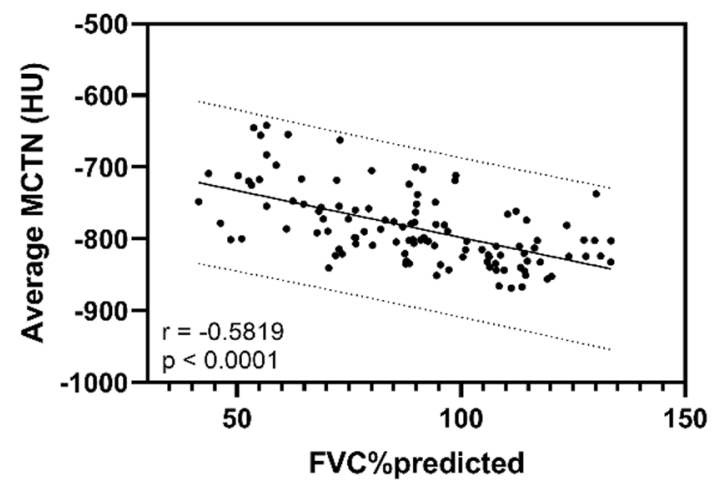

Fig. 3 DECT parameters correlation with PFT findings and TEI. It was shown the lung volume highly correlated with FVC, VC, TLC and DLCO respectively in $\mathbf{a}-\mathbf{d}$. It was shown the moderate to high correlation of $Z_{\text {eff }}$ value $(\mathbf{e}, \mathbf{f})$ and MCTN (g, h) with TEl and FVC\%predicted respectively. Lines show estimated regression (solid line) and 95\% confidence interval (dotted line) 

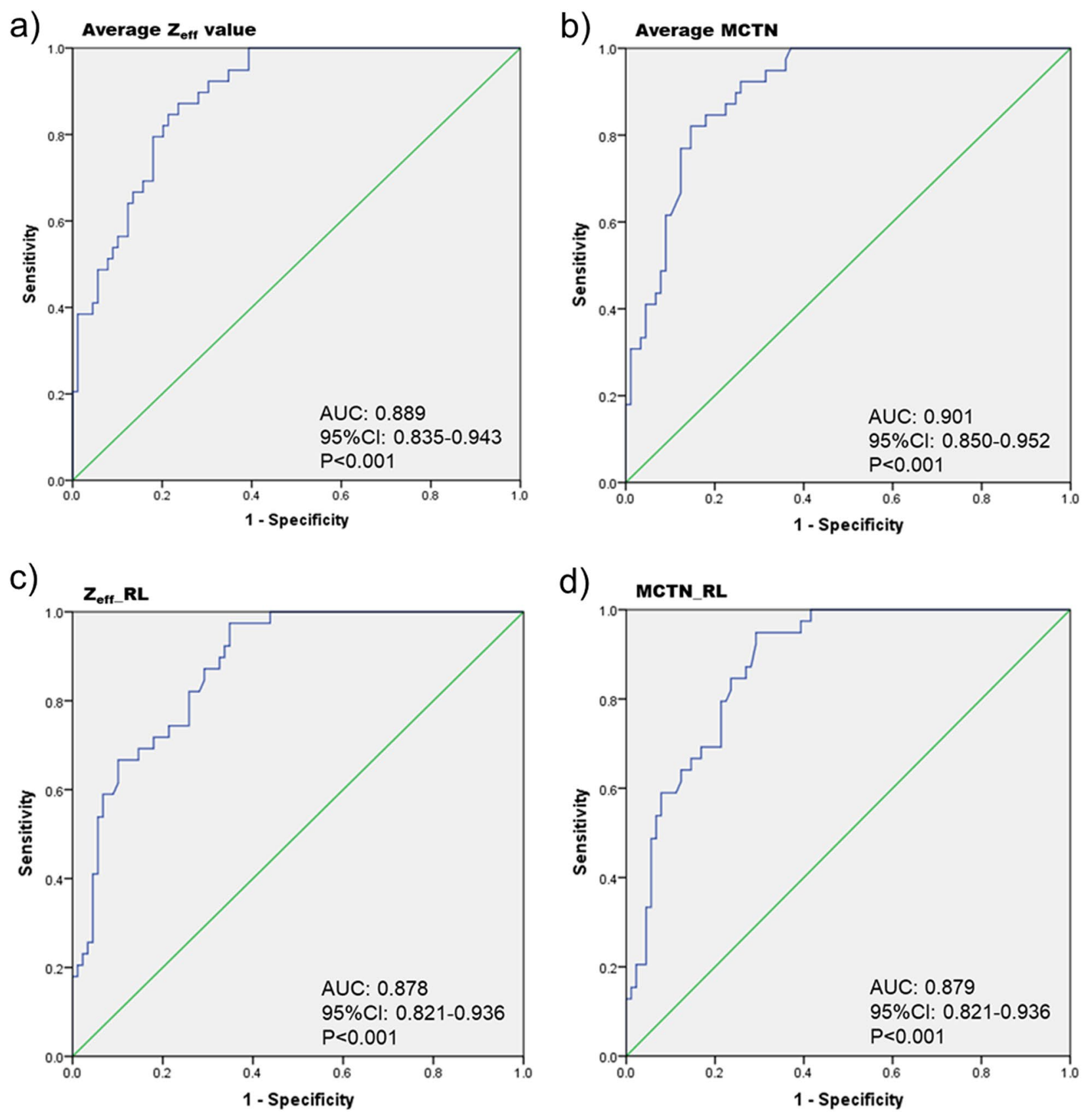

Fig. 4 Receiver operating characteristic curve to demonstrate the optimal cutoff value of DECT parameters to detect presence of extensive disease of CTD-ILD. The optimal cut-off value was $2.510,2.775,-762.30 \mathrm{HU}$ and $-746.50 \mathrm{HU}$ for average $Z_{\text {eff }}$ value, $Z_{\text {eff- }}$ RL, average MCTN and MCTN_RL, respectively. AUC area under the curve, Cl confidence interval, Z_RL $Z_{\text {eff }}$ value of right lower lung lobe, MCTN_RL monochromatic CT number of right lower lung lobe. Average $Z_{\text {eff }}$ value $Z_{\text {eff }}$ value averaged over the whole lung, Average MCTN monochromatic CT number at 70 keV averaged over the whole lung

or interstitial fibrosis, leading to increasing mixture of various cells and intercellular matrix [39]. The interplay of multiple cell types, their cellular components, and intercellular matrix involved in the pathomechanism defines the diseases pattern, extent, function and severity of CTD-ILD. $Z_{\text {eff }}$ and MCTN could represent the characteristics of the composite atoms for the mixture of various cells, materials or compounds in lesions [26], reflecting the severity of diseases. Lung fibrosis, including CTD-ILD, is characterized by restricted lung 
Table 3 Comparison the DECT parameters according to respiratory symptoms (dyspnea and cough based on Borg dyspnea score and LCQ)

\begin{tabular}{|c|c|c|c|c|c|c|c|c|}
\hline & \multirow[t]{2}{*}{ No symptom } & \multirow[t]{2}{*}{ Dyspnea or Cough } & \multirow[t]{2}{*}{ Dyspnea \& Cough } & \multirow[t]{2}{*}{$F / X^{2}$} & \multirow[t]{2}{*}{$P$ value } & \multicolumn{3}{|c|}{$P$ value } \\
\hline & & & & & & 0 VS 1 & 0 VS 2 & 1 VS 2 \\
\hline Total-No & 49 & 59 & 37 & & & & & \\
\hline Age (y) & $51.88 \pm 9.15$ & $49.95 \pm 8.45$ & $47.84 \pm 11.33$ & 1.918 & .151 & & & \\
\hline BMI $\left(\mathrm{kg} / \mathrm{m}^{2}\right)$ & $22.84 \pm 2.90$ & $23.22 \pm 3.43$ & $23.16 \pm 3.60$ & 0.196 & .822 & & & \\
\hline Female (\%) & $42(85.7)$ & $52(88.1)$ & $36(97.3)$ & 3.297 & .192 & & & \\
\hline Han nationality (\%) & $44(89.8)$ & $54(91.5)$ & $36(97.3)$ & 1.746 & .444 & & & \\
\hline Former/current smoker (\%) & $6(12.2)$ & $10(16.9)$ & $1(2.7)$ & 4.479 & .107 & & & \\
\hline Comorbidity (\%) & $25(51.0)$ & $40(67.8)$ & $20(54.1)$ & 3.533 & .171 & & & \\
\hline Lung Volume $\left(\mathrm{cm}^{3}\right)$ & $3276.91 \pm 901.49$ & $3180.67 \pm 1023.01$ & $2587.13 \pm 937.77$ & 6.182 & .003 & .605 & .001 & .004 \\
\hline V_RL & $536.65 \pm 270.32$ & $524.26 \pm 277.83$ & $360.07 \pm 248.04$ & 5.561 & .005 & .811 & .003 & .004 \\
\hline V_RM & $344.79 \pm 127.27$ & $359.11 \pm 147.82$ & $331.00 \pm 152.42$ & 0.452 & .637 & .604 & .658 & .348 \\
\hline V_RU & $892.29 \pm 272.61$ & $856.15 \pm 232.68$ & $779.98 \pm 253.04$ & 2.136 & .122 & .459 & .043 & .152 \\
\hline V_LL & $500.43 \pm 243.27$ & $466.75 \pm 50.63$ & $313.56 \pm 237.36$ & 6.777 & .002 & .478 & .001 & .003 \\
\hline V_LU & $1002.76 \pm 293.67$ & $974.40 \pm 293.11$ & $802.52 \pm 317.40$ & 5.358 & .006 & .625 & .003 & .007 \\
\hline Average $Z_{\text {eff }}$ value & $2.375 \pm 0.425$ & $2.398 \pm 0.581$ & $2.914 \pm 0.629$ & 12.819 & .000 & .830 & .000 & .000 \\
\hline Z_RL & $2.886 \pm 0.720$ & $2.852 \pm 0.790$ & $3.603 \pm 0.896$ & 11.778 & .000 & .829 & .000 & .000 \\
\hline Z_RM & $2.141 \pm 0.349$ & $2.174 \pm 0.627$ & $2.557 \pm 0.691$ & 6.584 & .002 & .766 & .001 & .002 \\
\hline Z_RU & $1.957 \pm 0.269$ & $2.015 \pm 0.504$ & $2.350 \pm 0.524$ & 9.140 & .000 & .506 & .000 & .000 \\
\hline Z_LL & $2.879 \pm 0.720$ & $2.881 \pm 0.716$ & $3.612 \pm 0.833$ & 13.184 & .000 & .992 & .000 & .000 \\
\hline Z_LU & $2.011 \pm 0.299$ & $2.067 \pm 0.474$ & $2.450 \pm 0.618$ & 9.796 & .000 & .542 & .000 & .000 \\
\hline Average MCTN (HU) & $-790.51 \pm 40.61$ & $-788.55 \pm 53.41$ & $-740.97 \pm 59.80$ & 11.904 & .000 & .843 & .000 & .000 \\
\hline MCTN_RL & $-740.12 \pm 71.29$ & $-744.80 \pm 74.51$ & $-674.32 \pm 83.27$ & 11.260 & .000 & .750 & .000 & .000 \\
\hline MCTN_RM & $-813.31 \pm 34.47$ & $-810.46 \pm 57.87$ & $-776.43 \pm 61.91$ & 6.147 & .003 & .779 & .002 & .002 \\
\hline MCTN_RU & $-831.61 \pm 24.88$ & $-826.00 \pm 46.11$ & $-795.73 \pm 50.54$ & 8.541 & .000 & .486 & .000 & .001 \\
\hline MCTN_LL & $-741.27 \pm 68.51$ & $-740.63 \pm 66.50$ & $-671.70 \pm 85.87$ & 12.545 & .000 & .964 & .000 & .000 \\
\hline MCTN_LU & $-826.24 \pm 27.76$ & $-820.85 \pm 43.03$ & $-786.65 \pm 58.80$ & 9.033 & .000 & .522 & .000 & .000 \\
\hline
\end{tabular}

$0=$ no respiratory symptom, $1=$ with dyspnea or cough, $2=$ with dyspnea and cough

Total-No. $=145$

$D E C T$ dual-energy computed tomography, LCQ Leicester cough questionnaire, CTD-ILD connective tissue disease-associated interstitial lung disease, BMI body mass index, $V R L$ volume of right lower lung lobe, $V R M$ volume of right middle lung lobe, $V \quad R U$ volume of right upper lung lobe, $V+L L$ volume of left lower lung lobe, $V+L U$ volume of left upper lung lobe, $Z_{-} R L Z_{\text {eff }}$ value of right lower lung lobe, $Z_{-} R M Z_{\text {eff }}$ value of right middle lung lobe, $Z_{-} R U Z_{\text {eff }} v a l u e$ of right upper lung lobe, $Z_{-} L L Z_{\text {eff }}$ value of left lower lung lobe, $Z \_L U Z_{\text {eff }}$ value of left upper lung lobe, MCTN monochromatic CT number at 70 keV, MCTN_RL monochromatic CT number of right lower lung lobe, $M C T N \_R M$ monochromatic CT number of right middle lung lobe, $M C T N \_R U$ monochromatic $C T$ number of right upper lung lobe, $M C T N \_L L$ monochromatic $C T$ number of left lower lung lobe, $M C T N \_L U$ monochromatic $C T$ number of left upper lung lobe

expansion [40]. In present study, DECT parameter lung volume highly correlated with VC, TLC and FVC: the lung volume reduced, accompanied by a reduction of $\mathrm{VC}$, TLC and FVC in severe CTD-ILD patients, indicating restricted ventilatory defect [40], which might due to the reduction in lung compliance. Meanwhile, LV performed better than $\mathrm{Z}_{\text {eff }}$ value and MCTN in mental health evaluation. Therefore, DECT parameters exhibited complementary evaluation capacity of CTD-ILD.

It is well-known that ILD in usual interstitial pneumonitis or non-special interstitial pneumonia pattern frequently locates in lower lung lobes [41]. Our study also showed that the DECT parameters of bilateral lower lung lobes had the highest AUC to differentiate extensive CTD-ILD from the limited CTD-ILD than the ones of middle lobe or upper lobes. The possible reason is that the lesions in lower lung lobes are more serious with more cells, materials or compounds, while DECT is good at detecting and distinguishing them. At the same time, $\mathrm{Z}_{\text {eff }}$ value and MCTN of middle lung lobe also showed relative higher AUC which corresponded with visual changes in middle lung lobe lesions. The middle lung lobe, with unique ventilation, perfusion and being flanked by two fissures, might affect its specific compliance. It suggested that the distribution of disease should be considered in the severity evaluation of CTD-ILD by DECT.

DECT was indicated to be superior to texture analysis or machine learning methods in view of the degrees of correlation with PFTs in this study. The parameters 
Table 4 Binary logistic regression analysis of univariate analysis and multivariate analysis with dyspnea of CTD-ILD patient

\begin{tabular}{|c|c|c|c|c|c|c|c|c|c|c|}
\hline & Univaria & Analy & & & & Multivar & te Ana & & & \\
\hline & $\beta$ value & SE & Wals & OR $(95 \% \mathrm{Cl})$ & $P$ & $\beta$ value & SE & Wals & OR $(95 \% \mathrm{Cl})$ & $P$ \\
\hline Age (y) & -0.020 & 0.018 & 1.328 & $0.980(0.946-1.014)$ & .249 & -0.042 & 0.020 & 4.522 & $0.959(0.923-0.997)$ & .033 \\
\hline Gender (male/female) & 1.417 & 0.669 & 4.488 & $4.125(1.112-15.304)$ & .034 & & & & & \\
\hline Han nationality & 0.093 & 0.630 & 0.022 & 1.097 (0.319-3.770) & .883 & & & & & \\
\hline BMI $\left(\mathrm{kg} / \mathrm{m}^{2}\right)$ & 0.063 & 0.051 & 1.516 & $1.065(0.963-1.179)$ & .218 & & & & & \\
\hline Former/current smoke & -0.875 & 0.561 & 2.436 & $0.417(0.139-1.251)$ & .119 & & & & & \\
\hline Comorbidity & 0.063 & 0.338 & 0.035 & $1.065(0.549-2.065)$ & .852 & & & & & \\
\hline Lung volume (L) & -0.461 & 0.188 & 5.982 & $0.631(0.436-0.913)$ & .014 & & & & & \\
\hline Average $Z_{\text {eff }}$ value & 1.096 & 0.325 & 11.379 & $2.991(1.583-5.653)$ & .001 & 1.293 & .347 & 13.895 & 3.644 (1.846-7.192) & .000 \\
\hline Average MCTN (HU) & 0.011 & 0.003 & 10.888 & $1.012(1.005-1.018)$ & .001 & & & & & \\
\hline Type of CTD & & & 2.398 & & .302 & & & & & \\
\hline SCTD vs UCTD & 0.507 & 0.428 & 1.398 & $1.660(0.717-3.843)$ & .237 & & & & & \\
\hline MCTD vs UCTD & 0.952 & 0.649 & 2.151 & $2.591(0.726-9.246)$ & .142 & & & & & \\
\hline
\end{tabular}

Total, No. $=145$, significance with $p<0.05$

CTD-ILD connective tissue disease associated interstitial lung disease, $B M I$ body mass index, MCTN monochromatic CT number at 70 keV, $C T D$ connective tissue disease, SCTD specific connective tissue disease, UCTD undifferentiated connective tissue disease, MCTD mixed connective tissue disease

Table 5 Binary logistic regression analysis of univariate analysis and multivariate analysis with cough of CTD-ILD patient

\begin{tabular}{|c|c|c|c|c|c|c|c|c|c|c|}
\hline & Univaria & Analy & & & & Multivar & te Ana & & & \\
\hline & $\beta$ value & SE & Wals & OR $(95 \% \mathrm{Cl})$ & $P$ & $\beta$ value & SE & Wals & OR $(95 \% \mathrm{Cl})$ & $P$ \\
\hline Age (y) & -0.033 & 0.018 & 3.316 & $0.967(0.933-1.003)$ & .069 & -0.075 & 0.023 & 10.462 & $0.927(0.886-0.971)$ & .001 \\
\hline Gender (male/female) & 0.189 & 0.556 & 0.116 & $1.208(0.407-3.592)$ & .733 & & & & & \\
\hline Han nationality & 1.355 & 0.801 & 2.862 & $3.875(0.807-18.614)$ & .091 & 1.499 & 0.864 & 3.010 & $4.479(0.823-24.365)$ & .083 \\
\hline $\operatorname{BMI}\left(\mathrm{kg} / \mathrm{m}^{2}\right)$ & -0.025 & 0.051 & 0.238 & $0.975(0.882-1.078)$ & .626 & & & & & \\
\hline Former/current smoke & -0.137 & 0.524 & 0.068 & $0.872(0.312-2.435)$ & .794 & & & & & \\
\hline Comorbidity & 0.171 & 0.341 & 0.253 & $1.187(0.609-2.314)$ & .615 & & & & & \\
\hline Lung volume (L) & -0.401 & 0.187 & 4.595 & $0.670(0.464-0.966)$ & .032 & & & & & \\
\hline Average $Z_{\text {eff }}$ value & 0.771 & 0.302 & 6.504 & $2.161(1.195-3.907)$ & .011 & 1.132 & 0.361 & 9.826 & $3.101(1.528-6.294)$ & .002 \\
\hline Average MCTN (HU) & 0.008 & 0.003 & 6.318 & $1.008(1.002-1.015)$ & .012 & & & & & \\
\hline Type of CTD & & & 4.909 & & .086 & & & 10.637 & & .005 \\
\hline SCTD vs UCTD & -0.728 & 0.424 & 2.947 & $0.483(0.210-1.109)$ & .086 & -1.402 & 0.515 & 7.420 & $0.246(0.090-0.675)$ & .006 \\
\hline MCTD vs UCTD) & -1.417 & 0.693 & 4.185 & $0.242(0.062-0.942)$ & .041 & -2.490 & 0.825 & 9.101 & $0.083(0.016-0.418)$ & .003 \\
\hline
\end{tabular}

Total, No. $=145$, significance with $\mathrm{p}<0.05$

CTD-ILD connective tissue disease associated interstitial lung disease, BMI body mass index, MCTN monochromatic CT Number at 70 keV, CTD connective tissue disease,SCTD specific connective tissue disease, UCTD undifferentiated connective tissue disease, MCTD mixed connective tissue disease

of DECT significantly associated with FVC\% predicted, DLCO, VC, or TLC with correlation coefficients of absolute value ranged from 0.54 to 0.89 . In previous studies, the absolute value of correlation coefficients in fibrosis quantitative score based on the texture metrics [17] with $\mathrm{FVC} \%$ predicted ranged from 0.41 to 0.60 , and with DLCO\% predicted ranged from 0.37 to 0.68 . Combined with ILD patterns, the coefficients of radiologists' assessment with CALIPER could achieve 0.73 , similar to our study. However, all of them need additional software development and long supervised or non-supervised learning. As a novel quantitative technique, DECT with the inherent software is convenient for quantitative analysis in a shorter time. Besides, the DECT quantitative analysis doesn't need an experienced specialist to define the interstitial patterns. Therefore, DECT seems to have more advantages in evaluating CTD-ILD patients.

The DECT parameters ( $\mathrm{LV}, \mathrm{Z}_{\text {eff }}$ value, or MCTN) were associated with the symptoms or life quality of CTD-ILD patients in our study. Respiratory symptoms are the manifestations of structural and inflammatory changes [45] or decline in pulmonary function. The DECT parameters 
can reflect the material composition and lung structural compliance, and significantly correlated with PFT. That explains why the DECT parameters could differentiate the severity of respiratory symptoms and be their risk factors. Life quality is impaired in ILD patients, influencing clinical prognosis [46]. And SF-36 was recommended to be applied in the comprehensive evaluation of CTD-ILD patients [38]. However, SF-36 was rarely applied in quantitative computed tomography assessment research. In our study, it was indicated that LV, along with age, comorbidity, confirmed CTD and severer cough, contributed to the mental health-related quality of life in CTD-ILD patients. Therefore, DECT could not only complement pulmonary physiology function, but also provide comprehensive clinical features in CTD-ILD patients.

Although MCTN measurement $[47,48]$ was reported to be relatively unreliable compared to $\mathrm{Z}_{\text {eff }}$ value, and the precise of measurement may be affected by the presence of surrounding tissues, newer DECT systems, such as the one used in our study have improved accuracy of MCTN with optimized hardware and calculation [49]. Furthermore, MCTN was reported to have highest accuracy near the $70 \mathrm{keV}$ energy level which was selected in our study [50].

While our results were valuable, we recognized there were still several limitations in our study. Firstly, given that there was a significant imbalance in the radiological patterns (usual interstitial pneumonitis and non-special interstitial pneumonia) among the included patients, radiological patterns analysis was not conducted. Secondly, to avoid radiate patients twice, the CT images were reconstructed from DECT data set, thus we could not directly compare CT numbers of conventional CT with MCTN and $Z_{\text {eff }}$ value in DECT to document their advantage. Thirdly, the data set was from a single center with a small sample size of a cross sectional study, so it could not be readily generalized. Since our population was ILD patients with CTDs, caution should be exercised in extrapolating our findings to other causes of ILD. We recognized these limitations and believed that further validation of our preliminary results was warranted to predict the progression, acute exacerbation, or death.

\section{Conclusion}

In conclusion, our results suggested that DECT parameters were able to structurally and functionally discriminate severe CTD-ILD patients from mild ones. We believed that DECT could represent an accurate and convenient alternative quantitative tool in evaluating CTD-ILD.

\section{Abbreviations}

CTD-ILD: Connective tissue disease-associated interstitial lung disease; GSI: Gemstone spectral imaging; CT: Computed tomography; DECT: Dual-energy computed tomography; HRCT: High-resolution computed tomography; LV: Lung volume; $Z_{\text {eff: }}$ Effective atomic number; Effective-Z; MCTN: Monochromatic CT number at $70 \mathrm{keV}$; HU: Hounsfield units; keV: Kilo electron volt; RA: Rheumatoid arthritis; SSc: Systemic sclerosis/scleroderma; PM/DM: Polymyositis/dermatomyositis; SLE: Systemic lupus erythematosus; SjS: Sjögren syndrome; IPAF: Interstitial pneumonia with autoimmune features; UCTD: Undifferentiated connective tissue disease; SCTD: Specific connective tissue disease; MCTD: Mixed connective tissue disease; RL: Right lower lung lobe; LL: Left lower lung lobe; RM: Right middle lung lobe; RU: Right upper lung lobe; LU: Left upper lung lobe; AUC: Area under the curve; ROC: Receiver operating characteristic; Cl: Confidence interval; PCS: Physical component summary; MCS: Mental component summary.

\section{Supplementary Information}

The online version contains supplementary material available at https://doi. org/10.1186/s12931-022-01972-4.

\begin{abstract}
Additional file 1: Table S1. Comparison the DECT parameters among TEI $>20 \%$ and TEI $\leq 20 \%$.Table S2. Comparison DECT parameters among Group mild (FVC\% $\geq 80 \%$ \& DLCO $\geq 80 \%$ ), Group moderate (the indeterminate) and Group severe (FVC $\% \leq 50 \%$ or DLCO $0 \leq 50 \%$ ). Table S3. Comparison demographic characteristics, volume, Zeff value and monochromatic CTN between limited CTD-ILD/extensive CTD-ILD group and the control group. Table S4. Pearson/Spearman correlation coefficient Matrix of DECT parameters with SF-36, TEl and PFT findings. Table S5. Receiver operating characteristic curve to demonstrate optimal cutoff value of DECT parameters to detect presence of extensive disease of CTDILD. Table S6. Comparison the DECT parameters among different degree of dyspnea according to Borg dyspnea score. Table S7. Comparison the DECT parameters among different severity cough symptom according to LCQ with the cut-off value 17. Table S8. Linear Regression Analysis to Define the Variables Contribution to PCS in patient with CTD-ILD. Table S9. Linear Regression Analysis to Define the Variables Contribution to MCS in patient with CTD-ILD. Table S10. Binary Logistic Regression Analysis of Univariate Analysis and Multivariate Analysis with Dyspnea of CTD-ILD patient. Table S11. Binary Logistic Regression Analysis of Univariate Analysis and Multivariate Analysis with Cough of CTD-ILD patient.
\end{abstract}

\section{Acknowledgements}

The authors are grateful to all radiologists and physicians at the Department of Radiology and Rheumatology who have contributed to advancing the field of DECT through their clinical collaborations.

\section{Authors' contributions}

LC conceived the idea of the DECT assessment study, designed the study, performed the statistical analysis, researched literatures and drafted the manuscript. MZ participated in the design of the study, researched literatures, helped to draft the manuscript and revised the manuscript. HYL conceived the idea of study, researched literatures, carried out the data collection process and helped to draft the manuscript. TY researched literatures and participated in the data analysis. WJL researched literatures and helped to interpretate the results. YLZ collected the raw data. QBX and ZLL interpretated the results and revised the manuscript. HJW and FML conceived the idea of the study, participated in its design and coordination, interpretated the results and revised the manuscript. All authors read and approved the final manuscript.

\section{Funding}

This study has been supported by $1 \cdot 3.5$ project for disciplines of excellence, West China Hospital, Sichuan University (ZYJC18021), Sichuan Science and Technology Program (No. 2021YFQ0030) and Sichuan Science and Technology Program (No. 2020YFH0073).

Availability of data and materials

The datasets used and/or analyzed during the current study are available from the corresponding author on reasonable request. 


\section{Declarations}

Ethics approval and consent to participate

This study was approved by Ethics Committee on Biomedical Research (2020-216) at West China Hospital. Subject consent was waived.

\section{Consent for publication}

Not applicable.

\section{Competing interests}

Not applicable.

\begin{abstract}
Author details
'Department of Respiratory and Critical Care Medicine, West China Hospital, Sichuan University, No. 37 Guo Xue Xiang, Chengdu 610041, China. 'Laboratory of Pulmonary Immunology and Inflammation, Frontiers Science Center for Disease-Related Molecular Network, Sichuan University, No.2222 Xin Chuan Road, Chengdu 610041, Sichuan, China. ${ }^{3}$ Department of Radiology, West China Hospital, Sichuan University, Chengdu 610041, China. ${ }^{4}$ Department of Rheumatology, West China Hospital, Sichuan University, Chengdu 610041, China.
\end{abstract}

Received: 27 October 2021 Accepted: 24 February 2022

Published online: 05 March 2022

\section{References}

1. Hu Y, Wang L-S, Wei Y-R, Du S-S, Du Y-K, He X, Li N, Zhou Y, Li Q-H, Su $Y$-L, et al. Clinical characteristics of connective tissue disease-associated interstitial lung disease in 1,044 Chinese Patients. Chest. 2016;149:201-8.

2. Jee AS, Sheehy R, Hopkins P, Corte TJ, Grainge C, Troy LK, Symons K, Spencer LM, Reynolds PN, Chapman S, et al. Diagnosis and management of connective tissue disease-associated interstitial lung disease in Australia and New Zealand: A position statement from the Thoracic Society of Australia and New Zealand. Respirology (Carlton, Vic). 2021;26:23-51.

3. Fischer A, du Bois R. Interstitial lung disease in connective tissue disorders. Lancet (London, England). 2012;380:689-98.

4. Jeganathan N, Sathananthan M. Connective tissue disease-related interstitial lung disease: prevalence, patterns, predictors, prognosis, and treatment. Lung. 2020;198:735-59.

5. Li L, Zuo X, Luo H, Li Y, You Y, Duan L, Zhang W, Zhao H, Li T, Ning W, et al. Mortality trend of inpatients with connective tissue diseases: 2005-2014. J Central South Univ Med Sci. 2017:42:927-33.

6. Fischer A, Chartrand S. Assessment and management of connective tissue disease-associated interstitial lung disease. Sarcoidosis Vascul Diffuse Lung Dis. 2015;32:89.

7. Gunnarsson R, Aaløkken TM, Molberg $\varnothing$, Lund MB, Mynarek GK, Lexberg AS, Time K, Dhainaut ASS, Bertelsen L-T, Palm O, et al. Prevalence and severity of interstitial lung disease in mixed connective tissue disease: a nationwide, cross-sectional study. Ann Rheum Dis. 2012;71:1966-72.

8. Vij R, Strek ME. Diagnosis and treatment of connective tissue diseaseassociated interstitial lung disease. Chest. 2013;143:814-24.

9. Caron M, Hoa S, Hudson M, Schwartzman K, Steele R. Pulmonary function tests as outcomes for systemic sclerosis interstitial lung disease. Eur Respir Rev. 2018;27:56.

10. Szeinuk J, Noonan CW, Henschke CI, Pfau J, Black B, Miller A, Yankelevitz DF, Liang M, Liu Y, Yip R, et al. Pulmonary abnormalities as a result of exposure to Libby amphibole during childhood and adolescence-The Pre-Adult Latency Study (PALS). Am J Ind Med. 2017;60:20-34.

11. Wells AU. Pulmonary function tests in connective tissue disease. Semin Respir Crit Care Med. 2007;28:379-88.

12. Aduen JF, Zisman DA, Mobin SI, Venegas C, Alvarez F, Biewend M, Jolles $\mathrm{HI}$, Keller CA. Retrospective study of pulmonary function tests in patients presenting with isolated reduction in single-breath diffusion capacity: implications for the diagnosis of combined obstructive and restrictive lung disease. Mayo Clin Proc. 2007;82:48-54.

13. Chen J, Yang Z, Yuan Q, Xiong D-X, Guo L-Q. Prediction models for pulmonary function during acute exacerbation of chronic obstructive pulmonary disease. Physiol Meas. 2021:41:125010.
14. Jacob J, Hirani N, van Moorsel CHM, Rajagopalan S, Murchison JT, van Es HW, Bartholmai BJ, van Beek FT, Struik MHL, Stewart GA, et al. Predicting outcomes in rheumatoid arthritis related interstitial lung disease. Eur Resp J. 2019;53:234.

15. Hoffmann-Vold A-M, Fretheim H, Halse A-K, Seip M, Bitter H, Wallenius M, Garen T, Salberg A, Brunborg C, Midtvedt $\varnothing$, et al. Tracking impact of interstitial lung disease in systemic sclerosis in a complete nationwide cohort. Am J Respir Crit Care Med. 2019;200:1258-66.

16. Lynch DA, Godwin JD, Safrin S, Starko KM, Hormel P, Brown KK, Raghu G, King TE, Bradford WZ, Schwartz DA, Richard Webb W. High-resolution computed tomography in idiopathic pulmonary fibrosis: diagnosis and prognosis. Am J Respir Crit Care Med. 2005;172:488-93.

17. Kim HJ, Brown MS, Chong D, Gjertson DW, Lu P, Kim HJ, Coy H, Goldin JG. Comparison of the quantitative CT imaging biomarkers of idiopathic pulmonary fibrosis at baseline and early change with an interval of 7 months. Acad Radiol. 2015;22:70-80.

18. Maldonado F, Moua T, Rajagopalan S, Karwoski RA, Raghunath S, Decker PA, Hartman TE, Bartholmai BJ, Robb RA, Ryu JH. Automated quantification of radiological patterns predicts survival in idiopathic pulmonary fibrosis. Eur Respir J. 2014;43:204-12

19. So A, Nicolaou S. Spectral computed tomography: fundamental principles and recent developments. Korean J Radiol. 2021;22:86-96.

20. Johnson TRC. Dual-energy CT: general principles. AJR Am J Roentgenol. 2012;199:S3-8.

21. Schenzle JC, Sommer WH, Neumaier K, Michalski G, Lechel U, Nikolaou K, Becker CR, Reiser MF, Johnson TRC. Dual energy CT of the chest: how about the dose? Invest Radiol. 2010;45:347-53.

22. Hwang HJ, Hoffman EA, Lee CH, Goo JM, Levin DL, Kauczor H-U, Seo JB. The role of dual-energy computed tomography in the assessment of pulmonary function. Eur J Radiol. 2017;86:320-34.

23. Meier A, Wurnig M, Desbiolles L, Leschka S, Frauenfelder T, Alkadhi H. Advanced virtual monoenergetic images: improving the contrast of dualenergy CT pulmonary angiography. Clin Radiol. 2015;70:1244-51.

24. Lehmann LA, Alvarez RE, Macovski A, Brody WR, Pelc NJ, Riederer SJ, Hall AL. Generalized image combinations in dual KVP digital radiography. Med Phys. 1981;8:659-67.

25. Remy-Jardin M, Faivre JB, Pontana F, Molinari F, Tacelli N, Remy J. Thoracic applications of dual energy. Semin Respir Crit Care Med. 2014;35:64-73.

26. Gonzalez-Perez V, Arana E, Barrios M, Bartres A, Cruz J, Montero R, Gonzalez M, Deltoro C, Martinez-Perez E, De Aguiar-Quevedo K, Arraras M. Differentiation of benign and malignant lung lesions: dual-energy computed tomography findings. Eur J Radiol. 2016;85:1765-72.

27. Huh S, Lee H. Pulmonary bone cement embolism: CT angiographic evaluation with material decomposition using gemstone spectral imaging. Korean J Radiol. 2014;15:443-7.

28. Hwang HJ, Lee SM, Seo JB, Lee JS, Kim N, Lee SW, Oh YM. Visual and quantitative assessments of regional xenon-ventilation using dual-energy CT in asthma-chronic obstructive pulmonary disease overlap syndrome: a comparison with chronic obstructive pulmonary disease. Korean J Radiol. 2020;21:1104-13.

29. Bradley B, Branley HM, Egan JJ, Greaves MS, Hansell DM, Harrison NK, Hirani N, Hubbard R, Lake F, Millar AB, et al. Interstitial lung disease guideline: the British Thoracic Society in collaboration with the Thoracic Society of Australia and New Zealand and the Irish Thoracic Society (vol 63, Suppl V, pg v1, 2008). Thorax. 2008;63:1029-1029.

30. Fischer A, Antoniou KM, Brown KK, Cadranel J, Corte TJ, du Bois RM, Lee JS, Leslie KO, Lynch DA, Matteson EL, et al. An official European Respiratory Society/American Thoracic Society research statement: interstitial pneumonia with autoimmune features. Eur Respir J. 2015:46:976-87.

31. Collard HR, Ryerson CJ, Corte TJ, Jenkins G, Kondoh Y, Lederer DJ, Lee JS, Maher TM, Wells AU, Antoniou KM, et al. Acute exacerbation of idiopathic pulmonary fibrosis: an international working group report. Am J Respir Critical Care Med. 2016;194:265-75.

32. Ponikowski P, Voors AA, Anker SD, Bueno H, Cleland JGF, Coats AJS, Falk V, González-Juanatey JR, Harjola V-P, Jankowska EA, et al. 2016 ESC Guidelines for the diagnosis and treatment of acute and chronic heart failure: The Task Force for the diagnosis and treatment of acute and chronic heart failure of the European Society of Cardiology (ESC). Developed with the special contribution of the Heart Failure Association (HFA) of the ESC. Eur J Heart Failure. 2016;18:891-975. 
33. Murray MP, Turnbull K, MacQuarrie S, Pentland JL, Hill AT. Validation of the Leicester Cough Questionnaire in non-cystic fibrosis bronchiectasis. Eur Respir J. 2009;34:125-31.

34. Miller MR, Hankinson J, Brusasco V, Burgos F, Casaburi R, Coates A, Crapo $R$, Enright P, van der Grinten CPM, Gustafsson P, et al. Standardisation of spirometry. Eur Respir J. 2005;26:319-38.

35. Hu S, Hoffman EA, Reinhardt JM. Automatic lung segmentation for accurate quantitation of volumetric X-ray CT images. IEEE Trans Med Imaging. 2001:20:490-8.

36. Goh NSL, Desai SR, Veeraraghavan S, Hansell DM, Copley SJ, Maher TM, Corte TJ, Sander CR, Ratoff J, Devaraj A, et al. Interstitial lung disease in systemic sclerosis - a simple staging system. Am J Respir Crit Care Med. 2008;177:1248-54.

37. Khanna D, Nagaraja V, Tseng C-H, Abtin F, Suh R, Kim G, Wells A, Furst DE, Clements PJ, Roth MD, et al. Predictors of lung function decline in scleroderma-related interstitial lung disease based on high-resolution computed tomography: implications for cohort enrichment in systemic sclerosis-associated interstitial lung disease trials. Arthritis Res Ther. 2015; 17:372.

38. Khanna D, Clements PJ, Furst DE, Chon Y, Elashoff R, Roth MD, Sterz MG, Chung J, FitzGerald JD, Seibold JR, et al. Correlation of the degree of dyspnea with health-related quality of life, functional abilities, and diffusing capacity for carbon monoxide in patients with systemic sclerosis and active alveolitis: results from the Scleroderma Lung Study. Arthritis Rheum. 2005:52:592-600.

39. Hansell DM, Bankier AA, MacMahon H, McLoud TC, Müller NL, Remy J. Fleischner Society: glossary of terms for thoracic imaging. Radiology. 2008;246:697-722.

40. Tsuchiya N, Yamashiro T, Murayama S. Decrease of pulmonary blood flow detected by phase contrast MRI is correlated with a decrease in lung volume and increase of lung fibrosis area determined by computed tomography in interstitial lung disease. Eur J Radiol. 2016;85:1581-5.

41. Raghu G, Remy-Jardin M, Myers JL, Richeldi L, Ryerson CJ, Lederer DJ, Behr J, Cottin V, Danoff SK, Morell F, et al. Diagnosis of Idiopathic Pulmonary Fibrosis: An Official ATS/ERS/JRS/ALAT Clinical Practice Guideline. Am J Respir Crit Care Med. 2018;198:e44-68.

42. Humphries SM, Yagihashi K, Huckleberry J, Rho B-H, Schroeder JD, Strand M, Schwarz MI, Flaherty KR, Kazerooni EA, van Beek EJR, Lynch DA. Idiopathic pulmonary fibrosis: data-driven textural analysis of extent of fibrosis at baseline and 15-month follow-up. Radiology. 2017;285:270-8.

43. Matsumoto K, Jinzaki M, Tanami Y, Ueno A, Yamada M, Kuribayashi S. Virtual monochromatic spectral imaging with fast kilovoltage switching: improved image quality as compared with that obtained with conventional 120-kVp CT. Radiology. 2011;259:257-62.

44. Yabuki H, Minowa M, Adachi $Y$, Hara Y, Katsumata H, Matsuura Y. Resecting a giant malignant lung tumor in a patient with unilateral acute interstitial pneumonitis. Respir Investig. 2020;58:220-4.

45. Chung KF, Pavord ID. Prevalence, pathogenesis, and causes of chronic cough. Lancet (London, England). 2008;371:1364-74.

46. Lubin M, Chen H, Elicker B, Jones KD, Collard HR, Lee JS. A comparison of health-related quality of life in idiopathic pulmonary fibrosis and chronic hypersensitivity pneumonitis. Chest. 2014;145:1333-8.

47. Ueguchi T, Ogihara R, Yamada S. Accuracy of Dual-Energy Virtual Monochromatic CT Numbers: comparison between the single-source projection-based and dual-source image-based methods. Acad Radiol. 2018;25:1632-9.

48. Goodsitt MM, Christodoulou EG, Larson SC. Accuracies of the synthesized monochromatic CT numbers and effective atomic numbers obtained with a rapid kVp switching dual energy CT scanner. Med Phys. 2011;38:2222-32.

49. Jacobsen MC, Schellingerhout D, Wood CA, Tamm EP, Godoy MC, Sun J, Cody DD. Intermanufacturer Comparison of Dual-Energy CT iodine quantification and monochromatic attenuation: a phantom study. Radiology. 2018:287:224-34.

50. Darras KE, McLaughlin PD, Kang H, Black B, Walshe T, Chang SD, Harris AC, Nicolaou S. Virtual monoenergetic reconstruction of contrast-enhanced dual energy CT at 70keV maximizes mural enhancement in acute small bowel obstruction. Eur J Radiol. 2016:85:950-6.

\section{Publisher's Note}

Springer Nature remains neutral with regard to jurisdictional claims in published maps and institutional affiliations.
Ready to submit your research? Choose BMC and benefit from:

- fast, convenient online submission

- thorough peer review by experienced researchers in your field

- rapid publication on acceptance

- support for research data, including large and complex data types

- gold Open Access which fosters wider collaboration and increased citations

- maximum visibility for your research: over $100 \mathrm{M}$ website views per year

At BMC, research is always in progress.

Learn more biomedcentral.com/submissions 